\title{
Medical education and the challenge of neurological disability
}

\author{
Christopher D Ward
}

\begin{abstract}
The neuroscience curriculum should take account of the needs of patients and families and both undergraduate and postgraduate education should be guided by three criteria for quality of medical care-clinical competence, communication (and teamwork), and professional values. The assessment and management of neurological disability requires specific knowledge, skills and attitudes which can be supported by medical education. Suggestions are given on some of the elements which might be included in a curriculum relevant to neurological disability. The implementation of appropriate programmes is discussed.
\end{abstract}

A good general education, valuable though it may be, is frequently less than we need to solve...our most pressing problems. ${ }^{1}$ (Robbins Report on Higher Education ${ }^{1}$ ).

The designers of the current NHS reforms reminded us that the function of health services is to meet the needs of people. ${ }^{2}$ The aim of medical education, according to a recent Governmental Steering Group, is "to produce doctors ... who are able to meet the present and future needs of the health services" ${ }^{3}$ This paper suggests ways in which education can contribute to improving services for people with neurological disabilities. The first part discusses educational goals relevant to neurological disability. The second part considers how undergraduate and postgraduate education should be implemented.

\section{EDUCATIONAL GOALS FOR NEUROLOGICAL DISABILITY}

One of the maxims of British medical education (and especially neurology ${ }^{4}$ ) is that there is no substitute for a good grounding in clinical medicine. However, as the Robbins report on higher education commented, "a good general education, valuable though it may be, is frequently less than we need . . .". ${ }^{1}$ It is not safe to assume that the needs of patients are automatically addressed by the basic education we provide at present.

A patient might reasonably ask a doctor: Do you know your stuff? Can we communicate with each other? What do you regard as important? The questions are based on criteria for quality of care, ${ }^{5}$ but they form three planks upon which medical education should be founded: clinical competence, communication, and professional values.

\section{CLINICAL COMPETENCE \\ Skills}

The neurological patient who asks "Do you know your stuff?" is not merely expecting a doctor to make the correct diagnosis or to prescribe drugs appropriately. There is also a need to respond in an educated way to problems as diverse as sexual dysfunction in epilepsy, sleep disorders in Parkinson's disease, bladder function in multiple sclerosis or nutritional problems in Hungtington's disease. Education should provide skills which allow such problems to be recognised and channelled in appropriate directions.

Assessing a neurological patient from the rehabilitation point of view requires an extension of traditional neurological skills. There is still a need to ask the questions: where is the lesion? and what is the pathology? But we also need to ask: so what? For example, we are interested not just in whether there is spasticity (to imply a pyramidial lesion) but also how it affects gait; what problems (what disadvantages) does it produce? Gordon Holmes, who did much to establish the basic bed-side routine on which the clinical neurologist relies, acknowledged the importance of functional assessments when he wrote that "more can often be learned of a patient's disabilities by observing his ordinary actions... than by specific tests". 6

Measurement of deficit, and the organisation and recording of quantitative data require "critical appraisal" and "medical information science" skills, which were included among basic medical skills in the American report on the General Professional Education of the Physician (GPEP). ${ }^{7}$ Such skills are essential for effective audit ${ }^{8}$ and are especially important in chronic disabling conditions. For example, the management of epilepsy requires the critical interpretation of serial quantitative data and this skill is not automatically acquired in subsequent clinical practice. ${ }^{9}$

\section{Knowledge}

How do we decide what knowledge is needed for clinical competence? In its 1980 recomendations the General Medical Council (GMC) encouraged schools to teach students "the structure and function of the human body", which can be widely interpreted, and "the workings of the mind", which defy definition. ${ }^{10}$ A recent review of the early years of the Southampton undergraduate curriculum considered teaching methods and the problem of quantity (there should be less), but there was little comment about content, or about what 
should be learned. A "Delphic" Enquiry on Medical Education sponsored by the King's Fund in 1989-90 raised questions about teaching methods and curriculum overload and these concerns are apparent in the draft version of updated GMC recommendations, but again there is a lack of criteria by which specific items in the curriculum might be included or excluded.

The GPEP report recommended that medical teachers "work together to determine the essential clinical knowledge that all students must acquire". ${ }^{7}$ Curriculum recommendations for neurology would be controversial. To take one example, preclinical neuroscience courses often provide a lecture on the "normal" function of the basal ganglia. What is the educational value of this topic? The pathophysiology of Parkinson's disease is not fully explained by concepts of "normal" basal ganglia function-rather the reverse. ${ }^{11}$ Perhaps the importance of the basal ganglia is that they exemplify important general principles and are intrinsically interesting. Nevertheless, in a rational curriculum the physiology of the basal ganglia would be in competition with other items of equal or greater educational merit. Clinical understanding of the functional consequences of Parkinson's disease might be enhanced by a neuroscience curriculum which gave more emphasis to cognitive functions than to cerebral neurophysiology.

Clinical knowledge should also be rationalised and specified so far as possible. One well recognised problem is the location of most training (and hence virtually all neurology training) within hospitals. Not only is the students' diagnostic repertoire distorted, but they also have few opportunities to see the range of problems which present in the community, or to appreciate the need for continuing care. Few neurologists, and almost no students, have seen a patient in the terminal stages of Parkinson's disease. The limitations of the hospital perspective are well known to geriatricians. ${ }^{12}$ Their view of PD may be less diagnostically rigorous than that of neurologists, but it is perhaps more closely aligned to the experiences and needs of patients and families.

\section{COMMUNICATION}

The physician must be alerted to the many ways in which functional problems are expressed. Deficiencies in doctor-patient communication help to explain why problems such as impaired memory, dysphagia and sexual dysfunction are under-diagnosed.

An important reason for poor communication is the failure of doctors and others to function effectively with other professionals. Problems of any complexity will involve the cooperation of doctors with other profession$\mathrm{als}^{13}$ and students must therefore acquire the ability to utilise teamwork as a means of communicating with colleagues, and ultimately with the patients and their families. ${ }^{7}$ Educational deficiencies could be one reason for the low level of teamwork in British general practice. ${ }^{14}$
PROFESSIONAL VALUES

Professional values, or more broadly "personal qualities, values and attitudes" medical education, or in spite of it. Medical education does not necessarily have a positive effect on attitudes. A recent survey of Southampton medical students suggested that the attitude of medical students to disability remained unchanged, or even became more negative, during clinical training. ${ }^{15}$

Attitudes are personal and they are shaped by individual experiences, and personal knowledge. ${ }^{16}$ How can a doctor share the unique subjective knowledge which a patient brings to the medical consultation? Many attempts have been made to give students the experience of wheelchair mobility, but people with chronic disabilities or with experience as long-term carers are apt to consider such exercises as marginal and misleading. Few students have had personal experience of significant disability and many do not have the maturity to appreciate the gulf which exists between having a subjective experience and merely intellectualising about it. Students sometimes have an opportunity to visit disabled people at home but will rarely witness or grow to understand the problems of a family at its wits' end. Some literary descriptions of the experience of living with disability are valuable, ${ }^{17}$ but many such descriptions give the impression that life with a chronic disability is lived in a state of euphoric triumph over adversity. Post cards from the trenches are a poor substitute for the experience of being continually under fire.

\section{Professional self image}

It can be sensed (but not often proved) that students and graduates find themselves unattracted by disability. In a survey of American students' selection of electives from 38 specialties the most popular choices were radiology, cardiology and emergency medicine; physical medicine and rehabilitation ranked thirty sixth. ${ }^{7}$ Some students express the view that rehabilitation is "not really medicine"; they have formed a system of professional values-a professional self image-in which disability plays little part.

Medical management of chronic disabling diseases has a tendency to substitute doctors' for patients' aims. This may be one reason for the low rate of referral of patients with Parkinson's disease from doctors to therapists and social services. ${ }^{18}{ }^{19}$ Epilepsy is another example of a condition in which the medical aspects of management tend to overshadow other equally urgent needs.

Prevailing professional values do not encourage teamwork. In Britain, the amount of shared training of nurses, therapists and medical students is negligible. There are few chances for students to encounter models of effective team work either in primary care or in hospital. These deficiencies could be remedied relatively easily.

Another aspect of rehabilitation which is not easily built into prevailing professional value systems is the concept of supporting a popula- 
tion of disabled people within a community over a period of time. The Royal Commission on Medical Education ${ }^{20}$ asserted that "students should be acquainted with the means of providing health services for the whole population". It is significant that the two electives which American students found even less popular than rehabilitation were public health and preventive medicine. ${ }^{7}$ These socially based, pro-active specialities do not conform to the professional image which attracts most students to medicine. Doctors address themselves to individuals, and only reluctantly to populations. Hospital based training encourages them to do so.

Professional values (and therefore medical education) eventually affect the quantity and quality of medical services. Several historical factors have contributed to the fact that neurological services are unequal to the needs of people with chronic disabling conditions ${ }^{2122}$ and are a source of dissatisfaction for general practitioners. $^{23}$ The teaching of eminent precursors such as Holmes, ${ }^{6}$ Walshe ${ }^{4}$ and Symonds ${ }^{24}$ established a professional self image for neurology which remains narrowly medical in scope. Training has been concentrated in super specialised centres in London and elsewhere, and British neurology has perhaps been slow to heed the question "Can I see you when, and where, I need you?". Postgraduate training should be designed to meet the needs of people well beyond the bounds of regional hospital based centres as the specialty itself expands.

\section{IMPLEMENTATION}

Is neurological disability an undergraduate subject?

The GPEP report recommended that teachers "in each medical specialty differentiate knowledge essential for medical students from knowledge essential for residents and fellows"? The view has been expressed (for example, in the King's Fund Enquiry referred to earlier) that rehabilitation is a postgraduate subject. There are, however, few opportunities to acquire a rehabilitation perspective after qualification. Medical specialties such as geriatrics, rehabilitation medicine and some branches of paediatrics and psychiatry provide experience only for a minority. Few opportunities arise during surgical training despite the fact that many surgical specialties such as urology and orthopaedics provide specialised services for disabled people. General practice provides little training in rehabilitation.

It seems that attributes such as an awareness of functional problems, and an ability to work effectively with colleagues and with the patients and their families in negotiating therapeutic goals, do not emerge as natural products of post-graduate experience and nor can they be grafted on at a late stage in training. They should therefore be built into basic medical education. Generic concepts of the management of disability are useful to all doctors because they can be transferred to clinical settings as diverse as paediatrics, orthopaedics, cardiology and psychiatry as well as to neurology. The same principles are fundamental to primary care where much of the burden of chronic disease must be managed.

\section{UNDERGRADUATE EDUCATION \\ Neurology}

Studies by Wilkinson have shown that undergraduate neurology teaching is unevenly developed and under-resourced in the United Kingdom, where eight of 28 schools provide no comprehensive lecture programme. ${ }^{25}$ Neurology has traditionally given priority to diagnostic skills, with a second place given to medical and surgical management. Neurology teachers do not always see it as part of their responsibility - and often lack the opportunity-to link students with therapists, psychologists, nurses, or social workers, or to demonstrate the daily functioning of patients and families in a natural setting. The situation may be changing since in Wilkinson's survey 14 of 26 medical schools considered that students were introduced to the concept of team management of chronic neurological conditions. Sixteen of 26 schools stated that exposure to patients with chronic neurological disability was "adequate" (although criteria for adequacy were not specified). In the last few years a small number of academic and National Health Service posts have been funded with an explicit commitment to both neurology and rehabilitation, and further posts would facilitate the development of disability teaching.

With governmental encouragement to link education with service needs ${ }^{3}$ the time is ripe to extend the educational territory of neurology from the "Where?" and "What?" to the "So what?" dimension. Neurologists should follow GPEP's recommendation in establishing those elements in the curriculum which are general to all graduates; those which neuroscience and neurology specifically should contribute to undergraduates; and those which are more appropriate to a postgraduate training programme. ${ }^{7}$ There is need for close liaison with parellel developments in rehabilitation medicine.

\section{Rehabilitation medicine}

In a recent survey, 20 medical schools claimed to provide structured teaching on disability and rehabilitation; five did not. Teaching was often "opportunistic", suggesting a lack of specific educational goals. The most likely specialties to provide such teaching were rheumatology (or "rheumatology and rehabilitation"), geriatrics, and primary care. ${ }^{26}$ In the United Kingdom there are currently only three academic departments of rehabilitation medicine. It is clear that undergraduate teaching related to disability is unevenly developed in Britain and does not commonly involve neurologists. Graduates therefore find themselves ill equipped to cope with disorders such as Parkinson's disease.

There have been few attempts to meet educational goals such as those outlined in the first part of this paper. The Prince of Wales Advisory Group organised a national conference on this subject in 1990. Andrew Haines, from the Department of Primary Care, 
University College Hospital, described a faculty-wide consultation which led to a proposed curriculum for disability and rehabilitation. In the USA, outline curricula have been published from the standpoint of physical medicine and rehabilitation. ${ }^{27} 28$ There is general agreement that personal experience is valuable and that disabled people should be directly involved in teaching programmes.

In Southampton, clinical students attend a seven session rehabilitation medicine course whose objectives are similar to those outlined by Kirby. ${ }^{27}$ The course, which has been designed and taught by doctors, a social worker, therapists, nurses, and a person with severe physical disability, will be described in detail in a separate publication. The course has a one week structure which limits opportunities for clinical experience and prevents students from following patients longitudinally. Continuity of care is poorly represented in hospital-based teaching programmes although the need for such a perspective has been recognised. ${ }^{29} \mathrm{~A}$ further problem with the brief rehabilitation attachment is that it tends to represent rehabilitation as yet another "minor specialty" rather than being relevant to the medical educational process as a whole.

Medical faculties should examine the curriculum as a whole in the light of identified educational objectives for disability and rehabilitation, taking into account whatever local resources are available for clinical experience. Many of the educational goals outlined in the first part of this paper can be achieved in a variety of settings. For example, interprofessional teamwork and structured problem-solving can be observed in some departments of geriatric medicine, palliative care, psychiatry, or mental handicap. Neurologists should play an important role in curriculum planning and teaching.

\section{Postgraduate education}

Postgraduate education for neurological disability should be guided by the principles outlined above, and we will restrict discussion to a few comments on training in primary care, rehabilitation medicine and neurology.

\section{Primary care}

Given that general practitioners must take responsibility for the largest proportion of patients with chronic disability, including all those who are too disabled to visit hospitals, it is surprising that general practitioner trainees rarely receive formal training in the management of disability. Unlike some of their hospital colleagues general practitioners are exposed to the everyday world in which functional problems arise and they are more likely to be made aware of how disabilities bring disadvantage. But experience is not synonymous with education. The GP environment often fails to provide models for inter-professional collaboration. ${ }^{14}$ The negotiation of therapeutic programmes, the routine evaluation of treatment, and the implementation of preventive strategies are not established features of training programmes or of routine practice.

At the postgraduate stage GPs should become acquainted with services and agencies for disabled people, and with other specific information. However, postgraduate training is more crucially involved in the formation of professinal values. It provides an opportunity to examine the role of the GP in preventive surveillance of groups of disabled people, and for models of inter-professional teamwork to be developed.

\section{Rehabilitation medicine}

Rehabilitation medicine is now a defined medical specialty in Britain. ${ }^{13}$ Specialists are trained to coordinate services and meet the needs of people with severe physical disability. If the model suggested by the Royal College of Physicians ${ }^{30}$ is adopted then one consultant would be appointed in each district. Additional consultants will be needed for specialised regional and supraregional centres. Senior registrar training programmes include relevant experience in the rehabilitation of rheumatological patients and amputees as well as neurological rehabilitation. Neurology is of especial importance since neurological conditions comprise a large proportion of the most severely disabling conditions, and experience within a neurology department would be invaluable at registrar or senior registrar level.

\section{Neurology}

There are strong arguments for training all neurologists in the assessment and management of neurological disability. It is regrettable that neurologists in the United Kingdom often reach consultant posts with no specific experience of the rehabilitative management of chronic disability. The Association of British Neurologists suggests that neurological rehabilitation is a desirable, but not a mandatory element in specialist training. ${ }^{31}$ I would suggest that postgraduate training in neurology should include experience of structured rehabilitation within a team, so that neurologists become fully acquainted with the principles of problem-based assessment and management and the conduct of case conferences. Such training will find its application in routine clinic work, not merely in the context of a specialised rehabilitation team. The attachment of neurology registrars to departments of rehabilitation or geriatric medicine would be valuable.

The development of rehabilitation medicine as a specialty does not reduce the need for neurologists to acquire experience in rehabilitation. Rehabilitation medicine specialists will only be responsible for a minority of disabling problems: virtually all chronic neurological conditions are in some sense disabling. Moreover, the intensive clinical training of a neurologist can make a unique contribution to the management of complex disabling disorders. Neurologists will continue to be needed by patients and their families such as those whose experiences of Parkinson's disease were 
so eloquently presented in the video "Personal View".32

This paper argues that medical education can contribute to improving services for people with neurological disabilities. Rehabilitation in its widest sense is basic to the practice of all branches of clinical medicine and its concepts should be built into the undergraduate curriculum. Medical schools should examine the content of the curriculum as a whole in the light of objectives defined by the needs of disabled people. Neurologists should contribute to such a faculty-wide process. In addition there is a need for a revised undergraduate curriculum specifically for neuroscience and neurology.

Postgraduate education retains the overall objectives of the undergraduate curriculum but is geared to specific specialist activities. Neurological training in particular should include specific experience in rehabilitation even if the trainee is not destined to be involved in a specialised team.

1 Report of the Committee on Higher Education (Cmnd 2154). London: HMSO, 1963: para 25.

2 HM Government. Working for Patients. London: HMSO 1988.

3 Steering Group on Undergraduate Medical and Dental Education, 2nd report. London: Health Publications Unit, HMSO, 1990:para 4.3.i.

4 Landau WM. Training of the neurologist for the $21 \mathrm{st}$ century Arch Neurol 1989;46:21-22.

5 Furnham A. Competence to practice medicine. In: R Ellis, ed. Professional competence and quality assurance in the caring professions. London: Chapman and Hall, 1988.

6 Holmes G. Clinical neurology (rev WB Matthews) Edinburgh: Churchill Livingstone, 1971

7 Association of American Medical Colleges. Physicians for the twenty-first century: Report of the Project Panel on the the twenty-fiss cenal enction of the physict general professional education of the physician and college preparation for

8 Hopkins A. Clinical audit and neurology J Neurol Neurosurg Psychtatry 1992;55:19-25.

9 Ward CD. Decision making in refractory epilepsy. J Neurol
Neurosurg Psychiatry 1986;49:781-4.

10 General Medical Council. Recommendations on basic medical education. 1980.

11 Marsden CD. The mysterious motor function of the basal ganglia. Neurology 1982;32:514-39.

12 Wilkinson $D$. The pyschogeriatrician's view: management of chronic disability in the community. J Neurol Neurosurg Psychiatry 1992;55:41-4.

13 McLellan DL. Neurology or rehabilitation medicine? $J$ Neurol Neurosurg Psychiatry.

14 Wilkin D, Hallam L, Leavey R, Metcalfe D. Anatomy of urban general practice. London: Tavistock Publications, 1987.

15 Duckworth S. The effect of medical education on the attitudes of medical students towards disabled people. Med Education 1988;22:501-5

16 Polanyi M. Personal knowledge: towards a post-critical philosophy. London: Routledge, Kegan, Paul, 1958.

17 Flint H. Return journey. London: Black Swan, 1988.

18 Mutch WJ, Strudwick A, Roy SK, Downie AW. Parkinson's disease: Disability, review and therapy. $B M J$ 1986;293: diseas

19 Oxtoby M. Parkinson's disease patients and their social needs London: Parkinson's Disease Society, 1982.

20 Report of the Royal Commission on Medical Education 1965-68. (Cmnd 3569). London: HMSO, 1968:115.

21 Langton Hewer D, Wood V. Neurology in the United Kingdom 1 Historical Development. J Neurol Neurosurg Psychiatry, 1992.

22 Langton Hewer D, Wood V. Neurology in the United Kingdom II Current neurological services for adults Neurol Neurosurg Psychiatry, 1992

23 Hicks NR, Baker IA. General practitioners' opinions of health services available to their patients $B M$ 1991;302:991-3.

24 Symonds CP. Neurology. In: PO Williams, D Brinton, eds. Careers in medicine London: Hodder and Stoughton, 1952: $39-42$.

25 Wilkinson IMS. A survey of undergraduate teaching of clinical neurology in the United Kingdom 1990. J Neurol clinical neurology in the United King
Neurosurg Psychiatry 1991;54:226-8.

26 Marshall J, Haines A. Survey of the teaching of disability and rehabilitation to medical undergraduates in the UK. and rehabilitation to medical unde

27 Kirby RL. The GPEP report on undergraduate medical education implications for rehabilitation medicine $\mathbf{A m}$ Phys Med 1987;66:184-91.

28 Katz RT, Sutin J, Keen M, Betts HB. A one-week rotation in physical medicine and rehabilitation. J Med Educ 1987 62:769-71.

29 Berger A, Schaffer S. An interdisciplinary continuity of care experience for pre-clinical medical students. $J$ Med Education 1986;61:771-3.

30 Royal College of Physicians. Physical Disability in 1986 and beyond 1986. Roy Coll Phys 1986.

31 Association of British Neurologists: Statement on Senior Registrar Training, 1987.

32 Pentland B. Parkinson's disease: the spectrum of disability $J$ Neurol Neurosurg Psychiatry 1992;55:32-5. 